\title{
The Role of Autophagy and Mitophagy in Huntington's Disease
}

\author{
Akhila Eswaran ${ }^{1}$, Crystale Siew Ying Lim² , Soi Moi Chye ${ }^{1}$, Anna Pick Kiong Ling ${ }^{1}$ and Rhun Yian Koh ${ }^{*}$ \\ ${ }^{1}$ Division of Applied Biomedical Science and Biotechnology, International Medical University, Malaysia \\ ${ }^{2}$ Department of Biotechnology, UCSI University, Malaysia
}

\begin{abstract}
Huntington's disease (HD) is an inherited autosomal-dominant neurodegenerative disorder that occurs due to mutations in the polyglutamine expansions of the Huntingtin protein (Htt). HD is characterised by the loss of cognitive and motor functions, as well as the development of emotional and psychiatric disturbances. The HD pathology is manifested through the cellular changes that arise due to the toxic functions of mutant $\mathrm{Htt}(\mathrm{mHtt}$ ). Autophagy is a lysosomal pathway that functions to remove damaged intracellular components while mitophagy is a selective form of autophagy involving mitochondria; and PINK1/Parkin-mediated mitophagy is the most well-understood pathway. Mitochondrial dysfunction and defects in mitophagy can be linked to the pathogenesis of HD. Previous research has shown that the presence of mHtt hinders mitophagy; while PINK1/Parkin-mediated mitophagy provides neuroprotection in HD. Hence, this review discusses the roles and regulations of mitophagy, along with an overview of mitophagy in HD.
\end{abstract}

Keywords: Huntington's disease; autophagy; mitophagy

\section{INTRODUCTION}

Huntington's disease (HD) was named in the 1980s, from the original name of Huntington's chorea given by George Huntington in 1872 , following the discovery of other nonmotor symptoms caused by the disease (Bruyn, 1968; Huntington's Disease Collaborative Research Group, 1993). $\mathrm{HD}$ is a progressive brain disorder characterised by the loss of motor and cognitive function, as well as the presence of emotional and psychiatric disturbances (Ross \& Tabrizi, 2011). The average lifespan of an individual following the onset of these symptoms ranges from 15 to 20 years; and the common causes of mortality are infections such as pneumonia, and injuries associated with falls (Sturrock \& Leavitt, 2010). Juvenile HD is a rare form of the disease that develops during childhood, which also results in motor dysfunction, cognitive disability, as well as mental disturbances (Tost et al., 2004). HD occurs mostly in the Lake Maracaibo district of Venezuela, with a prevalence of 700 per 100000 people, due to the inheritance of the allele from the same ancestor (Dayalu \& Albin, 2015; Frank, 2014).
Following Venezuela, European countries and United States recorded the next highest prevalence of HD. On the other hand, Japan and Finland have a low HD prevalence (Frank, 2014). The treatment of HD is purely symptomatic, as there are no known effective disease-modifying drugs that currently available for the disease (Cubo et al., 2006). Symptoms of HD are treated with either standard psychiatric drugs, physiotherapy or speech therapy (Phillips et al., 2008).

$\mathrm{HD}$ is an autosomal dominant neurodegenerative disease that arises when there is an expansion of CAG trinucleotide sequence repeats, which code for the polyglutamine (polyQ) region in the Huntingtin (Htt) protein. The polyQ region functions to stabilise protein-protein interactions and prevent protein misfolding, while the Htt protein plays a role in chemical signalling and protection from apoptosis. The Htt protein produced in normal individuals has less than 36 repeated glutamines in their polyQ region (Walker, 2007). The mutant $\mathrm{Htt}(\mathrm{mHtt})$ protein is a misfolded protein produced when these CAG repeats undergo abnormal 
expansion, forming more than the normal number of repeats (Sapp et al., 2007). The Htt gene is inherited equally between both genders, and those possessing a mutated copy of the gene will acquire the disease as it has high penetrance (Walker, 2007).

The HD pathology is manifested by the various cellular changes that occur due to the toxic functions of mHtt. As Htt can interact with multiple proteins, the presence of $\mathrm{mHtt}$ will affect numerous biological functions such as cell signals, transcription and intracellular transportation (Harjes \& Wanker, 2003; Sapp et. al., 2007; Walker, 2007; Clelland et al., 2008). The mHtt protein has a high tendency to undergo cleavage, creating shorter fragments that consist of the polyglutamine expansion (Rubinsztein \& Carmichael, 2003). These protein fragments then undergo aggregation prior to forming inclusion bodies within cells, which subsequently affect neuronal function (Rubinsztein \& Carmichael, 2003; Bates et al., 2015). The aggregated mHtt proteins cause cell death by affecting chaperone proteins, impairing cellular energy production and affecting genes expression (SadriVakili \& Cha, 2006; Bates et al., 2015). As a result, this could contribute to the manifestation of neurodegenerative diseases (Kumar \& Ratan, 2016). This review aims to give an overview of the functions, regulations and processes of mitophagy, as well as its roles in the pathogenesis of HD.

\section{AUTOPHAGY}

Autophagy is a strictly regulated lysosomal pathway that plays an imperative role in the removal of damaged intracellular components (Eskelinen, 2008; Kundu \& Thompson, 2008). The autophagy mechanism is activated in the presence of stress, for instance during amino acid starvation or accumulation of unfolded proteins (Ahlberg et al., 1982). The process of autophagy can be divided into three types (Figure 1), based on its route of delivering the intracellular components to lysosomes. Macroautophagy involves sequestration of the cargo away from the lysosome, whereby autophagosomes is used to sequester cargo and subsequently transport it to the lysosome (Yorimitsu \& Klionsky, 2005). Chaperone-mediated autophagy (CMA) does not use membranous structures to sequester cargo, but instead uses chaperones to identify cargo proteins that contain a particular pentapeptide motif. These substrates are then unfolded and translocated individually directly across the lysosomal membrane (Massey et al., 2004). In microautophagy, protrusions of the lysosomal membrane are used to capture cargo (Mijaljica et al., 2011).

Macroautophagy is the most common form of autophagy and is often referred to as autophagy itself. Macroautophagy generates nutrients during fasting under the control of amino acids and hormones, and contributes to the turnover and rejuvenation of cellular components (Bergamini et al., 2004). In this process, the portion of intracellular components intended for degradation is first sequestered inside specialised organelles known as autophagosomes. The autophagosomes then combine with lysosomal vesicles and subsequently delivered to the lysosomal hydrolytic enzymes to be degraded (Ahlberg et al., 1982). CMA is a proteolytic pathway whereby chaperones recognise the specific sequence signal on the cytosolic proteins and translocate them to the lysosomes through CMA receptors which are formed by lysosome-associated membrane glycoprotein 2 (LAMP-2A) proteins (Cuervo \& Dice, 1996). CMA has been involved in physiological and pathological processes such as lipid and carbohydrate metabolism, and neurodegenerative diseases, respectively (Alfaro et al., 2019). Microautophagy is the process whereby a portion of the cytoplasm containing the degradative components is engulfed by the lysosomal membrane and subsequently degraded by lysosomal hydrolytic enzymes (Ahlberg et al., 1982). In a previous study, isolated rat liver lysosomes were shown to engulf Percoll particles by protrusions of the lysosomal membrane, forming vesicles within the lysosome. Some of these particles were seen free-floating within the lysosomal lumen, presumably through rupture/lysis of the vesicles (Marzella et al., 1980). In addition, endosomal microautophagy transports soluble cytosolic proteins to the vesicles of late endosomal multivesicular bodies (Sahu et al., 2011). Microautophagy has a broad range of functions in biosynthetic transport, metabolic adaptation, organelle remodeling and quality control (Schuck, 2020).

Autophagy is an essential process that has many roles and functions in cells. Some of these include survival during amino acid starvation, clearance of proteins that are prone to aggregate, regulation of programmed cell death, regulation of cell growth, protection against intracellular pathogens and 
antigen presentation (Jurilj \& Pfeifer, 1990; Cuervo \& Dice, 1996; Kabeya et. al., 2000; Ishihara et. al., 2001; Mizushima et. al., 2001; Suzuki et. al., 2001; Kim et. al., 2002; Nazarko et. al., 2005; Hosokawa et. al., 2006; Klionsky, 2006; Schmid \& Münz, 2007; Xie \& Klionsky, 2007). These functions are further elaborated in Table 1. The mechanisms of autophagy can be categorised into selective and non-selective autophagy
(Wang \& Qin, 2013). In non-selective autophagy, cytoplasmic constituents are engulfed randomly into autophagosomes before getting transported to lysosomes for degradation (Stolz et al., 2014). On the other hand, selective autophagy carries out the degradation of specific substances. Mitophagy is an example of the selective autophagy (Stolz et. al., 2014; Veljanovski \& Batoko, 2014).

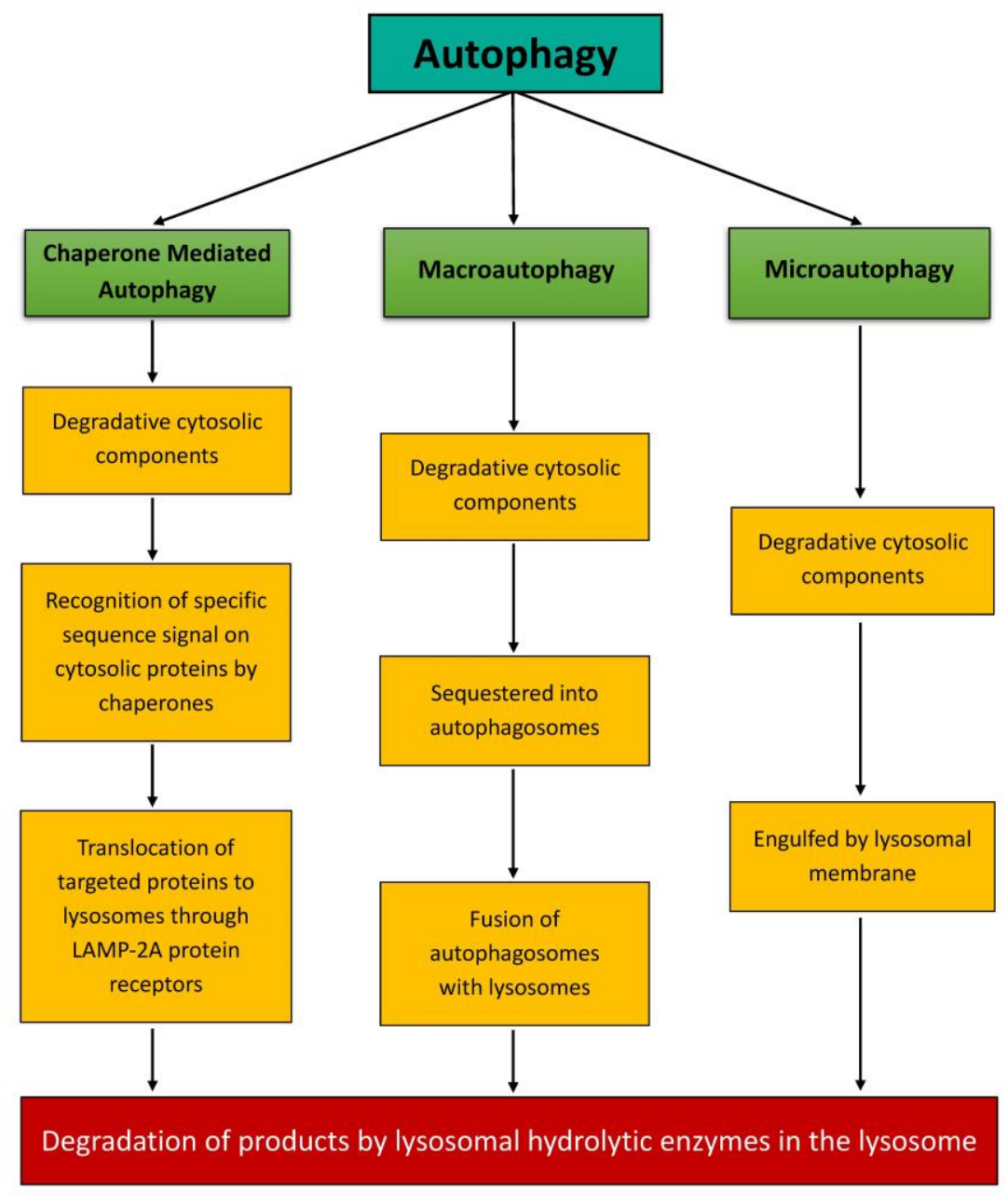

Figure 1. The different autophagy pathways in the degradation of cellular products. In macroautophagy, the portion of intracellular components intended for degradation is first sequestered into autophagosomes. The autophagosomes then combine with lysosomal vesicles and subsequently delivered to the lysosomal hydrolytic enzymes to be degraded. In chaperone-mediated autophagy (CMA), the chaperones recognise the specific sequence signal on the cytosolic proteins and translocate them to the lysosomes through CMA receptors which are formed by lysosome-associated membrane glycoprotein 2 (LAMP-2A) proteins. In microautophagy, a portion of the cytoplasm containing the degradative components is engulfed by the lysosomal membrane and subsequently degraded by lysosomal hydrolytic enzymes. 


\section{MITOPHAGY}

Mitochondria are essential organelles present in most eukaryotes that mainly function to regulate cellular energy homeostasis. Mitophagy is the mechanism responsible for the clearing and removal of damaged mitochondria. In this process, autophagosomes enclose the entire mitochondria and subsequently transport them to the lysosomes to be degraded (Ashrafi \& Schwarz, 2013). There are several types of mitophagy which differ from one another based on their process of mitochondrial engulfment, prior to its delivery to the lysosomes. These mitophagy processes follow a common receptor-mediated mechanism involving the binding of receptors in the autophagosomal membrane to the mitochondria (Wild et al., 2014).

Phosphatase and tensin homolog (PTEN)-induced putative kinase protein 1 (PINK1)/Parkin-mediated mitophagy is the most well-understood type of mitophagy (Figure 2) (Kitagishi et al., 2017). In this process, PINK1 is responsible for the activation of mitophagy, subsequently providing a protective role against apoptosis and mitochondrial dysfunction. Mutations in mitochondrial deoxyribonucleic acid (DNA), accumulation of dysfunctional mitochondria, as well as an increase in reactive oxygen species (ROS) production cause a decrease in the mitochondrial membrane potential. This prevents the degradation of PINK1, causing it to accumulate on the outer mitochondrial membrane. This subsequently causes the translocation and phosphorylation of Parkin (Geisler et. al., 2010; Lazarou et al., 2012). Parkin ubiquitylates outer mitochondrial membrane proteins which subsequently induces mitophagy by combining with targeted mitochondria. The ubiquitinated mitochondria are then degraded by lysosomes while proteasomes degrade the outer mitochondrial membrane proteins (Arano \& Imai, 2015; Maguire et al., 2017).

Table 1. A summary of the roles and functions of autophagy

\begin{tabular}{|c|c|}
\hline Role and function & Description \\
\hline $\begin{array}{l}\text { Protection against } \\
\text { intracellular pathogens }\end{array}$ & $\begin{array}{l}\text { Autophagy induction bypasses the maturation defect, which results in the production of } \\
\text { autophagolysosomes that subsequently kill the bacteria and intracellular pathogens } \\
\text { (Cuervo \& Dice, 1996). }\end{array}$ \\
\hline $\begin{array}{l}\text { Clearance of } \\
\text { aggregate-prone } \\
\text { proteins }\end{array}$ & $\begin{array}{l}\text { Autophagy plays a vital role in intracellular quality control by clearing the toxic aggregate- } \\
\text { prone proteins which are harmful to post-mitotic cells such as neurons (Klionsky, 2006). }\end{array}$ \\
\hline $\begin{array}{l}\text { Regulation of cell } \\
\text { growth }\end{array}$ & Autophagy negatively controls cell growth (Jurilj \& Pfeifer, 1990; Hosokawa et al., 2006). \\
\hline $\begin{array}{l}\text { Survival during } \\
\text { amino acid starvation }\end{array}$ & $\begin{array}{l}\text { Macroautophagy is induced shortly after amino acid starvation in order to supply energy } \\
\text { and metabolites to the cells by degrading intracellular cargo (Kabeya et al., 200o). }\end{array}$ \\
\hline $\begin{array}{l}\text { Regulation of } \\
\text { programmed cell death }\end{array}$ & $\begin{array}{l}\text { In cells that are unable to undergo apoptosis, autophagy proteins are required for the } \\
\text { autophagic cell death, which is also known as type II programmed cell death. Additionally, } \\
\text { autophagy plays a protective role during starvation by providing the cells with nutrients in } \\
\text { order to prevent apoptosis (Ishihara et. al., 2001; Mizushima et. al., 2001; Suzuki et. al., } \\
\text { 2001; Kim et. al., 2002; Nazarko et. al., 2005; Xie \& Klionsky, 2007). }\end{array}$ \\
\hline Antigen presentation & $\begin{array}{l}\text { Macroautophagy functions in antigen presentation by delivering the products of lysosomal } \\
\text { proteolysis to the major histocompatibility complex (MHC) class II molecules, which then } \\
\text { being presented for differentiation of Thelper (CD4+) cells (Schmid \& Münz, 2007). }\end{array}$ \\
\hline
\end{tabular}

In cardiolipin-mediated mitophagy, the phospholipid cardiolipin functions as a mitophagy receptor in response to depolarisation (Chu et. al., 2013; Maguire et al., 2017). Cardiolipin recruits the autophagosome machinery once it is externalised at the outer mitochondrial membrane as it contains a microtubule-associated protein light chain (LC)3binding motif (Chu et al., 2013). The mitochondrial membrane receptor-mediated mitophagy on the other hand, 
is the pathway in which outer mitochondrial membrane proteins such as B-cell lymphoma 2 and adenovirus E1B 19 kilodalton interacting protein 3 (BNIP3), FUN14 domaincontaining protein 1 (FUNDC1) and $\mathrm{BNIP}_{3}$-like protein (NIX) act as mitophagy receptors. The mitophagy process occurs under specific conditions in cells that possess these proteins as these proteins have the specific motifs required to facilitate interactions between mitochondria and the mitochondrial membrane protein, LC3 (Maguire et al., 2017).

Mitophagy is an essential mechanism that has various functions in both the normal physiological state and pathological conditions. In the normal state, mitophagy functions primarily in mitochondrial quality control, whereby it selectively clears damaged mitochondria and subsequently induces the generation of new mitochondria (Zhu et al., 2013). Besides, mitophagy regulates cell development and differentiation by removing redundant mitochondria (Sandoval et al., 2008). It also prevents cell death by removing damaged mitochondria that cause cell stress and apoptosis (Kubli \& Gustafsson, 2012). Another role of mitophagy is regulation of immune response. Through the removal of damaged mitochondria, mitophagy suppresses hyperactivation of inflammatory complexes which arise following an infection by foreign pathogens (Kim et al., 2016).

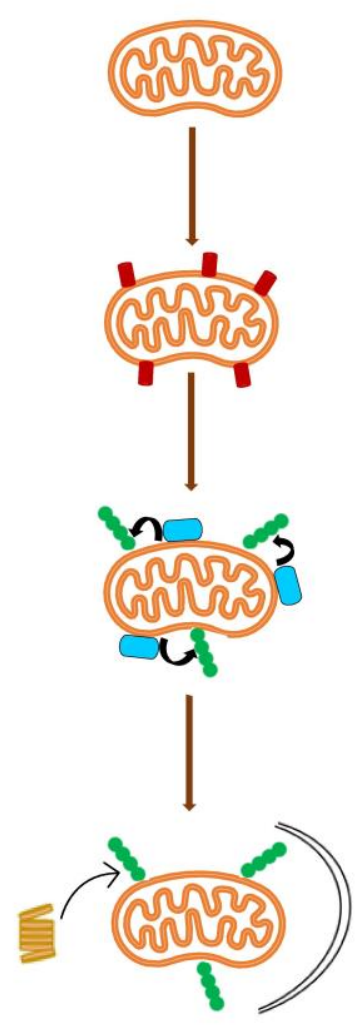

Mutations in mitochondrial DNA, accumulation of dysfunctional mitochondria, and increased production of ROS

Reduction in mitochondrial membrane potential

Accumulation of PINK1 on outer mitochondrial membrane

Phosphorylation of Parkin and polyubiquitin chain by PINK1

Activation and translocation of Parkin

Ubiquitination of outer membrane proteins by Parkin

Autophagic degradation of ubiquitinated mitochondria

Proteasomal degradation of outer membrane proteins

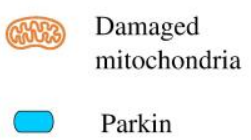

PINK1

Autophagosome
Polyubiquitin

Proteasome

Figure 2. The PINK1/Parkin-mediated mitophagy process. Mutations in mitochondrial deoxyribonucleic acid (DNA), accumulation of dysfunctional mitochondria, as well as an increase in reactive oxygen species (ROS) production cause a decrease in the mitochondrial membrane potential. This prevents the degradation of PINK1, causing it to accumulate on the outer mitochondrial membrane. This subsequently causes the translocation and phosphorylation of Parkin. Parkin ubiquitylates outer mitochondrial membrane proteins which subsequently induces mitophagy by combining with targeted mitochondria. The ubiquitinated mitochondria are then degraded by lysosomes while proteasomes degrade the outer mitochondrial membrane proteins. 
Mitophagy is also important in the control and regulation of pathological conditions. One of the examples is suppression of cancer development. Mitophagy is crucial in the removal of dysfunctional mitochondria which produce ROS. The increase in ROS production facilitates cancer development by inducing DNA damage and increasing abnormalities in gene expression (Palikaras et al., 2015). Additionally, mitophagy prevents development of certain heart and liver diseases. It provides cardioprotection to the heart in response to various stresses (Huang et al., 2011) while for the liver, it provides protection from potential injury and steatosis due to alcohol consumption (Williams et al., 2016). A reduction of mitophagy is associated with agingrelated dysfunctions of muscles and organs such as cardiac muscles, skeletal muscles, liver and the brain (Sun et al., 2015).

Mitophagy also plays a significant role in the prevention of neurodegenerative diseases. The maintenance of mitochondrial homeostasis is crucial for neuronal cell functions. As such, mitophagy is important in the eradication of damaged mitochondria, thereby preventing neuronal cell death (Kubli \& Gustafsson, 2012). If mitophagy is impaired, the accumulation of damaged mitochondria and increase in neuronal cell death will lead to neurodegenerative diseases (Cha et. al., 2015; Nah et al., 2015).

\section{AUTOPHAGY AND MITOPHAGY IN HUNTINGTON'S DISEASE}

Autophagy plays an imperative role in the clearance of damaged and misfolded proteins, thereby preventing accumulation and toxic effects of the abnormal proteins (Menzies et al., 2011). In HD, the presence of mHtt affects the autophagosome motility and vesicle trafficking, hence causing the autophagy disruption. To be specific, recognition of cargo by autophagosomes as well as subsequent axonal transport and substrate degradation are diminished in HD (Martinez-Vicente et. al., 2010; Wong \& Holzbaur, 2014). Brattås et al. (2021) found that overexpression of human transcription factor EB, a master regulator of autophagy, did not decrease mHTT aggregation while beclin 1 (an autophagic regulator that plays a key role in autophagosome formation) partially cleared mHTT aggregates. However, beclin 1 was only effective when administered early in the disease progression. Rhes GTPase interacts with beclin 1 and hence is required for autophagy (Mealer et al., 2014).

On the other hand, observations from some studies showed that experimental models expressing greater polyQ length of mHtt did not alter the autophagic functions, and the clearance of necessary substrates could still occur (Heng et al., 2010). These findings indicate that despite the presence of a polyQ mutation, Htt would still be able to carry out its function as a crucial player in autophagy and vesicle trafficking, if present in high numbers. Although it could possibly be beneficial to focus on the upregulation of autophagy alone, additional efforts should also be taken to correct the specific mechanistic defects to ensure the efficient clearance of mHtt and mitigation of its toxicity (Wong \& Holzbaur, 2014).

Interestingly, previous study found that HD could modulate autophagy function to have both toxic and protective effects on cells. mHTT could sequester the negative regulator of autophagy, mammalian target of rapamycin, to induce a higher rate of autophagy flux and protect against mHTT cytotoxicity (Ravikumar et al., 2004).

Mitophagy is necessary in the protection of neurons through the degradation of damaged mitochondria and maintenance of normal mitochondrial function (Zhang, 2013). Past studies have shown that the mitophagy process is affected in the presence of mHtt. The activation of PINK1/Parkin-mediated mitophagy however, has been shown to improve mitochondrial integrity and provide neuroprotection in HD models (Khalil et. al., 2015; Quinn et al., 2020). The mitophagic clearance of damaged and dysfunctional mitochondria is essential for the maintenance of neuronal cell homeostasis. Htt plays a role in mitophagy by enhancing the physical proximity of various protein complexes during the initiation of the process, as well as recruiting the essential receptors required in facilitating the binding of dysfunctional mitochondria to the autophagosomes. According to a study carried out by FrancoIborra and colleagues (2020), the formation of these protein complexes is affected in the presence of $\mathrm{mHtt}$, thereby leading to disruption of mitophagy. The presence of $\mathrm{mHtt}$ has been found to cause neurotoxicity and neurodegeneration in HD due to defect of mitophagy and disturbances in the normal mitochondrial dynamics (Bossy-Wetzel et. al., 2008; 
Franco-Iborra et al., 2020). Disruption of mitophagy leads to the accumulation of dysfunctional mitochondria and increased levels of oxidative stress, which contribute to the neurodegeneration in HD (Franco-Iborra et al., 2020). Additionally, defects in normal mitochondrial dynamics, along with other disturbances caused by mHtt such as compromised fission, fusion and organelle trafficking, give rise to bioenergetic failure, neuronal dysfunction and neuronal cell death in HD (Bossy-Wetzel et al., 2008).

PINK1/Parkin-mediated mitophagy is the main clearance pathway of dysfunctional mitochondria (Pickrell \& Youle, 2015). However, presence of mHtt affects normal interaction between the C-terminal of Htt and the autophagic receptors such as BCL2/adenovirus E1B $19 \mathrm{kDa}$ protein-interacting protein $3\left(\mathrm{BNIP}_{3}\right)$ and p62, resulting in compromised mitophagy in HD. This subsequently disrupts the recognition of ubiquitinated mitochondria by the LC3-containing isolation membranes, thereby preventing its degradation and resulting in its accumulation (Martinez-Vicente et. al., 2010; Ney, 2015; Rui et al., 2015). Khalil and colleagues (2015) investigated the role of impaired mitophagy in HD using Drosophila fly models which expressed neuronal Htt-ex1pQ93. When observations were made on the mitochondrial morphology affected by $\mathrm{mHtt}$, abnormal ring-shaped mitochondria were found to be present in the photoreceptor neurons. As these ring-shaped mitochondria were previously detected in mitophagy-deficient cells, further analysis was done to study the effects of PINK1 on these cells. It was found that the formation of abnormal mitochondria in HD fly models were reduced in the presence of PINK1 overexpression, which indicated its ability to counteract the toxic functions of mHtt. The neuroprotective properties of PINK1 was further observed by its ability to improve neuronal integrity and increase the survival rates of adult flies. Similarly, from the HD striatal cells derived from HdhQ111 knock-in mice, a decrease in the amount of ubiquitinated mitochondria targeted to autophagosomes, following mitophagy impairment was noted. This study also reported the ability of PINK1 overexpression in restoring mitophagy. These findings suggest that mitophagy is affected in the presence of $\mathrm{mHtt}$, however, increasing the PINK1/Parkinmediated mitophagy process might improve mitochondrial integrity and provide neuroprotection in HD (Khalil et al., 2015).

\section{CONCLUSION}

HD in general, is a devastating neurodegenerative disorder in which a cure is yet to be found. Autophagy and mitophagy are the essential process required for the maintenance of cellular homeostasis that plays a critical role in the prevention of several neurodegenerative diseases, including HD. Further understanding on the relationship between authophagy, mitophagy and HD is necessary for the development of treatment for HD.

\section{ACKNOWLEDGEMENT}

This work was supported by International Medical University, Malaysia [Grant No. BMS I-2018 (12)].

\section{REFERENCES}

Ahlberg, J, Marzella, L \& Glaumann, H 1982, 'Uptake and degradation of proteins by isolated rat liver lysosomes. Suggestion of a microautophagic pathway of proteolysis', Laboratory Investigation, vol. 4, pp. 523-532.

Alfaro, IE, Albornoz, A, Molina, A, Moreno, J, Cordero, K, Criollo, A \& Budini, M 2019, 'Chaperone mediated autophagy in the crosstalk of neurodegenerative diseases and metabolic disorders', Frontiers in Endocrinology, vol. 9, p. 778 .
Arano, T \& Imai Y 2015, Mitophagy regulated by the PINK1Parkin pathway, eds Ntuli TM, in Cell death-autophagy, apoptosis and necrosis, InTechOpen, London.

Ashrafi, G \& Schwarz, TL 2013, 'The pathways of mitophagy for quality control and clearance of mitochondria', Cell Death and Differentiation, vol. 20, pp. 31-42.

Bates, GP, Dorsey, R, Gusella, JF, Hayden, MR, Kay, C, Leavitt, BR, Nance, M, Ross, CA, Scahill, RI, Wetzel, R, Wild, EJ \& Tabrizi SJ 2015, 'Huntington disease', Nature.

Bergamini, E, Cavallini, G, Donati, A \& Gori, Z 2004, 'The role of macroautophagy in the ageing process, anti-ageing 
intervention and age-associated diseases', International Journal of Biochemistry \& Cell Biology, vol. 36, no. 12, pp. 2392-2404.

Bossy-Wetzel, E, Petrilli, A \& Knott, AB 2008, 'Mutant huntingtin and mitochondrial dysfunction', Trends in Neurosciences, vol. 31, no. 12, pp. 609-616.

Brattås, PL, Hersbach, BA, Madsen, S, Petri, R, Johan Jakobsson, J \& Pircs, K 2021, 'Impact of differential and time-dependent autophagy activation on therapeutic efficacy in a model of Huntington disease', Autophagy, vol. 17, no. 6, pp. 1326-1329.

Bruyn, GW 1968, Huntington's chorea: historical, clinical and laboratory synopsis, eds Vinken PJ \& Bruyn GW, in Handbook of clinical neurology, Elsevier, Amsterdam.

Cha, MY, Kim, DK \& Mook-Jung, I 2015, 'The role of mitochondrial DNA mutation on neurodegenerative diseases', Experimental Molecular Medicine, vol. 47, p. e150.

Chu, CT, Ji, J, Dagda, RK, Jiang, JF, Tyurina, YY, Kapralov, AA, Tyurin, VA, Yanamala, N, Shrivastava, IH, Mohammadyani, D, Wang, KZQ, Zhu, J, KleinSeetharaman, J, Balasubramanian, K, Amoscato, AA Borisenko, G, Huang, Z, Gusdon, AM, Cheikhi, A, Steer, EK, Wang, R, Baty, C, Watkins, S, Bahar, I, Bayir, H \& Kagan, VE 2013, 'Cardiolipin externalization to the outer mitochondrial membrane acts as an elimination signal for mitophagy in neuronal cells', Nature Cell Biology, vol. 15, pp. 1197-1205.

Clelland, CD, Barker, RA \& Watts, C 2008, 'Cell therapy in Huntington disease', Neurosurgical Focus, vol. 24, no. 3-4, p. E9.

Cubo, E, Shannon, KM, Tracy, D, Jaglin, JA, Bernard, BA, Wuu, J \& Leurgans, SE 2006, 'Effect of donepezil on motor and cognitive function in Huntington disease', Neurology, vol. 67, no. 7, pp. 1268-1271.

Cuervo, AM \& Dice, JF 1996, 'A receptor for the selective uptake and degradation of proteins by lysosomes', Science, vol. 273, pp. 501-503.

Dayalu, P \& Albin, RL 2015, 'Huntington disease: pathogenesis and treatment', Neurologic Clinics, vol. 33, no. 1, pp. 101-114.

Eskelinen, E 2008, 'New insights into the mechanisms of macroautophagy in mammalian cells', International Review of Cell and Molecular Biology, vol. 266, pp. 207247.

Franco-Iborra, S, Plaza-Zabala, A, Montpeyo, M, Sebastian, D, Vila, M \& Martinez-Vicente, M 2020, 'Mutant HTT (huntingtin) impairs mitophagy in a cellular model of Huntington disease', Autophagy, vol. 24, pp. 1-18.

Frank, S 2014, 'Treatment of Huntington's disease', Neurotherapeutics, vol. 11, no. 1, pp. 153-16o.

Geisler, S, Holmström, KM, Treis, A, Skujat, D, Weber, SS, Fiesel, FC, Kahle, PJ \& Springer, W 2010, 'The PINK1/Parkin-mediated mitophagy is compromised by PD-associated mutations', Autophagy, vol. 6, pp. 871-878.

Harjes, P \& Wanker, EE 2003, 'The hunt for huntingtin function: interaction partners tell many different stories', Trends in Biochemical Sciences, vol. 28, no. 8, pp. 425-433. Heng, MY, Duong, DK, Albin, RL, Tallaksen-Greene, SJ, Hunter, JM, Lesort, MJ, Osmand, A, Paulson, HL \& Detloff PJ 2010, 'Early autophagic response in a novel knock-in model of Huntington disease,' Human Molecular Genetetics, vol. 19, no. 19, pp. 3702-3720.

Hosokawa, N, Hara, Y \& Mizushima, N 2006, 'Generation of cell lines with tetracyclineregulated autophagy and a role for autophagy in controlling cell size', FEBS Letters, vol. 580, pp. 2623-2629.

Huang, C, Andres, AM, Ratliff, EP, Hernandez, G, Lee, P \& Gottlieb, RA 2011, 'Preconditioning involves selective mitophagy mediated by Parkin and p62/SQSTM1', PLOS One, vol. 6, no. 6, p. e20975.

Huntington's Disease Collaborative Research Group 1993, ‘A novel gene containing a trinucleotide repeat that is expanded and unstable on Huntington's disease chromosomes', Cell, vol. 72, pp. 971-983.

Ishihara, N, Hamasaki, M, Yokota, S, Suzuki, K, Kamada, Y, Kihara, A, Yoshimori, T, Noda, T \& Ohsumi, Y 2001, 'Autophagosome requires specific early Sec proteins for its formation and NSF/SNARE for vacuolar fusion', Molecular Biology of the Cell, vol. 12, pp. 3690-3702.

Jurilj, N \& Pfeifer, U 1990, 'Inhibition of cellular autophagy in kidney tubular cells stimulated to grow by unilateral nephrectomy', Virchows Archiv B, Cell Pathology including Molecular Pathology, vol. 59, pp. 32-37.

Kabeya, Y, Mizushima, N, Ueno, T, Yamamoto, A, Kirisako, T, Noda, T, Kominami, E, Ohsumi, Y \& Yoshimori, T 2000, 'LC3, a mammalian homologue of yeast Apg8p, is localized in autophagosome membranes after processing', The EMBO Journal, vol. 19, no. 21, pp. 5720-5728.

Khalil, B, Fissi, NE, Aouane, A, Cabirol-Pol, M, Rival, T \& Liévens, J 2015, 'PINK1-induced mitophagy promotes neuroprotection in Huntington's disease', Cell Death \& Disease, vol. 6, p. e1617. 
Kim, J, Huang, WP, Stromhaug, PE \& Klionsky, DJ 2002, 'Convergence of multiple autophagy and cytoplasm to vacuole components to a perivacuolar membrane compartment prior to de novo vesicle formation', Journal of Biological Chemistry, vol. 277, pp. 763-773.

Kim, MJ, Yoon, JH \& Ryu, JH 2016, 'Mitophagy: a balance regulator of $\mathrm{NLRP}_{3}$ inflammasome activation', BMB Reports, vol. 49, pp. 529-535.

Kitagishi, Y, Nakano, N, Ogino, M, Ichimura, M, Minami, A \& Matsuda, S 2017, 'PINK1 signaling in mitochondrial homeostasis and in aging', International Journal of Molecular Medicine, vol. 39, pp. 3-8.

Klionsky, DJ 2008, 'Neurodegeneration: good riddance to bad rubbish' Nature, vol. 441, pp. 819-820.

Kubli, DA \& Gustafsson, AB 2012, 'Mitochondria and mitophagy: the yin and yang of cell death control', Circulation Research, vol. 111, pp. 1208-1221.

Kumar, A \& Ratan, RR 2016, 'Oxidative stress and Huntington's disease: the good, the bad, and the ugly', Journal of Huntington's Disease, vol. 5, no. 3, pp. 217-237.

Kundu, M \& Thompson, CB 2008, 'Autophagy: basic principles and relevance to disease', Annual Review of Pathology, vol. 3, pp. 427-455.

Lazarou, M, Jin, SM, Kane, LA \& Youle, RJ 2012, 'Role of PINK1 binding to the TOM complex and alternate intracellular membranes in recruitment and activation of the E3 ligase Parkin', Developmental Cell, vol. 22, pp. 320333 .

Maguire, JJ, Tyurina, YY, Mohammadyani, D, Kapralov, AA, Anthonymuthu, TS, Qu, F, Amoscato, AA, Sparvero, LJ, Tyurin, VA, Planas-Iglesias, J, He, RR, Klein-Seetharaman, J, Bayır, H \& Kagan, VE 2017, 'Known unknowns of cardiolipin signaling: the best is yet to come', Biochimica et Biophysica Acta - Molecular and Cell Biology of Lipids, vol. 1862, no. 1, pp. 8-24.

Martinez-Vicente, M, Talloczy, Z, Wong, E, Tang, G, Koga, H \& Kaushik, S 2010, 'Cargo recognition failure is responsible for inefficient autophagy in Huntington's disease', Nature Neuroscience, vol. 13, pp. 567-576.

Marzella, L, Ahlberg, J \& Glaumann, H 1980, 'In vitro uptake of particles by lysosomes', Experimental Cell Research, vol. 129 , no. 2, pp. $460-466$.

Massey, A, Kiffin, R \& Cuervo, AM 2004, 'Pathophysiology of chaperone-mediated autophagy', International Journal of Biochemistry \& Cell Biology, vol. 36, no. 12, pp. 2420-2434.

Mealer, RG, Murray, AJ, Shahani, N, Subramaniam, S \& Snyder, SH 2014, 'Rhes, a striatal-selective protein implicated in Huntington disease, binds beclin-1 and activates autophagy', Journal of Biological Chemistry, vol. 289, pp. 3547-3554.

Menzies, FM, Moreau, K \& Rubinsztein, DC 2011, 'Protein misfolding disorders and macroautophagy', Current Opinion in Cell Biology, vol. 23, no. 2, pp. 190-197.

Mijaljica, D, Prescott, M \& Devenish, RJ 2011, 'Microautophagy in mammalian cells: revisiting a 40-yearold conundrum', Autophagy, vol. 7, no. 7, pp. 673-682.

Mizushima, N, Yamamoto, A, Hatano, M, Kobayashi, Y, Kabeya, Y, Suzuki, K, Tokuhisa, T, Ohsumi \& Y, Yoshimori, $\mathrm{T}$ 2001, 'Dissection of autophagosome formation using Apg5-deficient mouse embryonic stem cells', Journal of Cell Biology, vol. 152, pp. 657-667.

Nah, J, Yuan, J \& Jung, YK 2015, 'Autophagy in neurodegenerative diseases: from mechanism to therapeutic approach', Molecules and Cells, vol. 38, pp. 381-389.

Nazarko, TY, Huang, J, Nicaud, JM, Klionsky, DJ \& Sibirny, AA 2005, 'Sibirny Trs85 is required for macroautophagy, pexophagy and cytoplasm to vacuole targeting in Yarrowia lipolytica and Saccharomyces cerevisiae', Autophagy, vol. 1, pp. 37-45.

Ney, PA 2015, 'Mitochondrial autophagy: origins, significance, and role of $\mathrm{BNIP}_{3}$ and NIX', Biochimica et Biophysica Acta, vol. 1853, pp. 2775-2783.

Palikaras, K, Lionaki, E \& Tavernarakis, N 2015, 'Coordination of mitophagy and mitochondrial biogenesis during ageing in C. elegans', Nature, vol. 521, pp. 525-528. Phillips, W, Shannon, KM \& Barker, RA 2008, "The current clinical management of Huntington's disease", Movement Disorders, vol. 23, pp. 1491-1504.

Pickrell, AM \& Youle, RJ 2015, 'The roles of PINK1, parkin, and mitochondrial fidelity in Parkinson's disease', Neuron, vol. 85, pp. 257-273.

Quinn, PMJ, Moreira, PI, Ambrósio, AF \& Alves, CH 2020, 'PINK1/PARKIN signaling in neurodegeneration and neuroinflammation', Acta Neuropathologica Communications, vol. 8, no. 1, p. 189.

Ravikumar, B, Vacher, C, Berger, Z, Davies, JE, Luo, S, Oroz LG, Scaravilli, F, Easton, DF, Duden, R, O'Kane, CJ \& Rubinsztein, DC 2004, 'Inhibition of mTOR induces autophagy and reduces toxicity of polyglutamine expansions in fly and mouse models of Huntington disease', Nature Genetics, vol. 36, pp. 585-595. 
Ross, CA \& Tabrizi, SJ 2011, 'Huntington's disease: from molecular pathogenesis to clinical treatment', The Lancet Neurology, vol. 10, pp. 83-98.

Rubinsztein, DC \& Carmichael, J 2003, 'Huntington's disease: molecular basis of neurodegeneration', Expert Reviews in Molecular Medicine, vol. 5, no. 20, pp. 1-21.

Rui, YN, Xu, Z, Patel, B, Chen, Z, Chen, D, Tito, A, David, G, Sun, Y, Stimming, EF, Bellen, HJ, Cuervo, AM \& Zhang, S 2015, 'Huntingtin functions as a scaffold for selective macroautophagy', Nature Cell Biology, vol. 17, no. 3, pp. 262-275.

Sadri-Vakili, G \& Cha, JH 2006, 'Mechanisms of disease: histone modifications in Huntington's disease', Nature Clinical Practice Neurology, vol. 2, no. 6, pp. 330-338.

Sahu R, Kaushik S, Clement CC, Cannizzo ES, Scharf B, Follenzi, A, Potolicchio, I, Nieves, E, Cuervo, AM \& Santambrogio, L 2011, 'Microautophagy of cytosolic proteins by late endosomes' Developmental Cell, vol. 20, no. 1, pp. 131-139.

Sandoval, H, Thiagarajan, P, Dasgupta, SK, Schumacher, A, Prchal, JT, Chen, M \& Wang, J 2008, 'Essential role for Nix in autophagic maturation of erythroid cells', Nature, vol. 454, pp. 232-235.

Sapp, E, Schwarz, C, Chase, K, Bhide, PG, Young, AB, Penney, J, Vonsattel, JP, Aronin, N \& DiFiglia, M 1997, 'Huntingtin localization in brains of normal and Huntington's disease patients', Annals of Neurology, vol. 42, pp. 604-612.

Schmid, D \& Münz, C 2007, 'Innate and adaptive immunity through autophagy', Immunity, vol. 27, no. 1, pp. 11-21.

Schuck S 2020, 'Microautophagy - distinct molecular mechanisms handle cargoes of many sizes', vol. 133, no. 17, p. jcs246322.

Stolz, A, Ernst, A \& Dikic I 2014, 'Cargo recognition and trafficking in selective autophagy', Nature Cell Biology, vol. 16, pp. 495-501.

Sturrock, A \& Leavitt, BR 2010, 'The clinical and genetic features of Huntington disease', Journal of Geriatric Psychiatry and Neurology, vol. 23, no. 4, pp. 243-259.

Sun, N, Yun, J, Liu, J, Malide, D, Liu, C, Rovira, II, Holmström, KM, Fergusson, MM, Yoo, YH, Combs, CA \& Finkel, T 2015, 'Measuring in vivo mitophagy', Molecular Cell, vol. 6o, pp. 685-696.

Suzuki, K, Kirisako, T, Kamada, Y, Mizushima, N, Noda, T \& Ohsumi, Y 2001, 'The pre-autophagosomal structure organized by concerted functions of APG genes is essential for autophagosome formation', The EMBO Journal, vol. 20, pp. 5971-5981.
Tost, H, Wendt, CS, Schmitt, A, Heinz, A \& Braus, DF 2004, 'Huntington's disease: phenomenological diversity of a neuropsychiatric condition that challenges traditional concepts in neurology and psychiatry', American Journal of Psychiatry, vol. 161, no. 1, pp. 28-34.

Veljanovski, V \& Batoko, H 2014, 'Selective autophagy of nonubiquitylated targets in plants: looking for cognate receptor/adaptor proteins', Frontiers in Plant Science, vol. 5, p. 308.

Walker, FO 2007, 'Huntington's disease', Lancet, vol. 369, no. 9557, pp. 218-228.

Wang, Y \& Qin, ZH 2013, 'Coordination of autophagy with other cellular activities', Acta Pharmacologica Sinica, vol. 34, pp. 585-594.

Wild, P, McEwan, DG \& Dikic, I 2014, 'The LC3 interactome at a glance', Journal of Cell Science, vol. 127, pp. 3-9.

Williams, JA \& Ding, WX 2016, 'A mechanistic review of mitophagy and its role in protection against alcoholic liver disease', Biomolecules, vol. 5, pp. 2619-2642.

Wong, YC \& Holzbaur, EL 2014, 'The regulation of autophagosome dynamics by huntingtin and HAP1 is disrupted by expression of mutant huntingtin, leading to defective cargo degradation', Journal of Neuroscience, vol. 34, pp. 1293-1305.

Xie, Z \& Klionsky, DJ 2007, 'Autophagosome formation: core machinery and adaptations', Nature Cell Biology, vol. 9, pp. 1102-1109.

Yorimitsu, T \& Klionsky, DJ 2005, 'Autophagy: molecular machinery for self-eating', Cell Death and Differentiation, vol. 12, pp. 1542-1552.

Zhang, J 2013, 'Autophagy and mitophagy in cellular damage control', Redox Biology, vol. 1, no. 1, pp. 19-23.

Zhu, J, Wang, KZ \& Chu, CT 2013, 'After the banquet: mitochondrial biogenesis, mitophagy, and cell survival', Autophagy, vol. 9, pp. 1663-1676. 